\title{
Seven-Compartment Markov Decision Process Model for Control of Epidemic Infections
}

\author{
Ali Nasir ${ }^{1}$, Huma Baig ${ }^{1}$, and Muhammad Rafiq ${ }^{1}$ \\ ${ }^{1}$ University of Central Punjab
}

May 5, 2020

\begin{abstract}
This paper proposes a seven-compartment Markov decision process model for control of epidemic infections. Decision variables include vaccination, treatment, and quarantine. Cost function includes cost of treatment, cost of quarantine, and cost of vaccination. Transition probabilities have been represented by Bayesian network. Scalability of the proposed model has been discussed. Extensions of the proposed approach has also been included as well as comparison with the existing models. Superiority of the proposed approach has been elaborated through a case study.
\end{abstract}

\section{Hosted file}

SMCEI_pr_v4_single col.docx available at https://authorea.com/users/302390/articles/432505seven-compartment-markov-decision-process-model-for-control-of-epidemic-infections

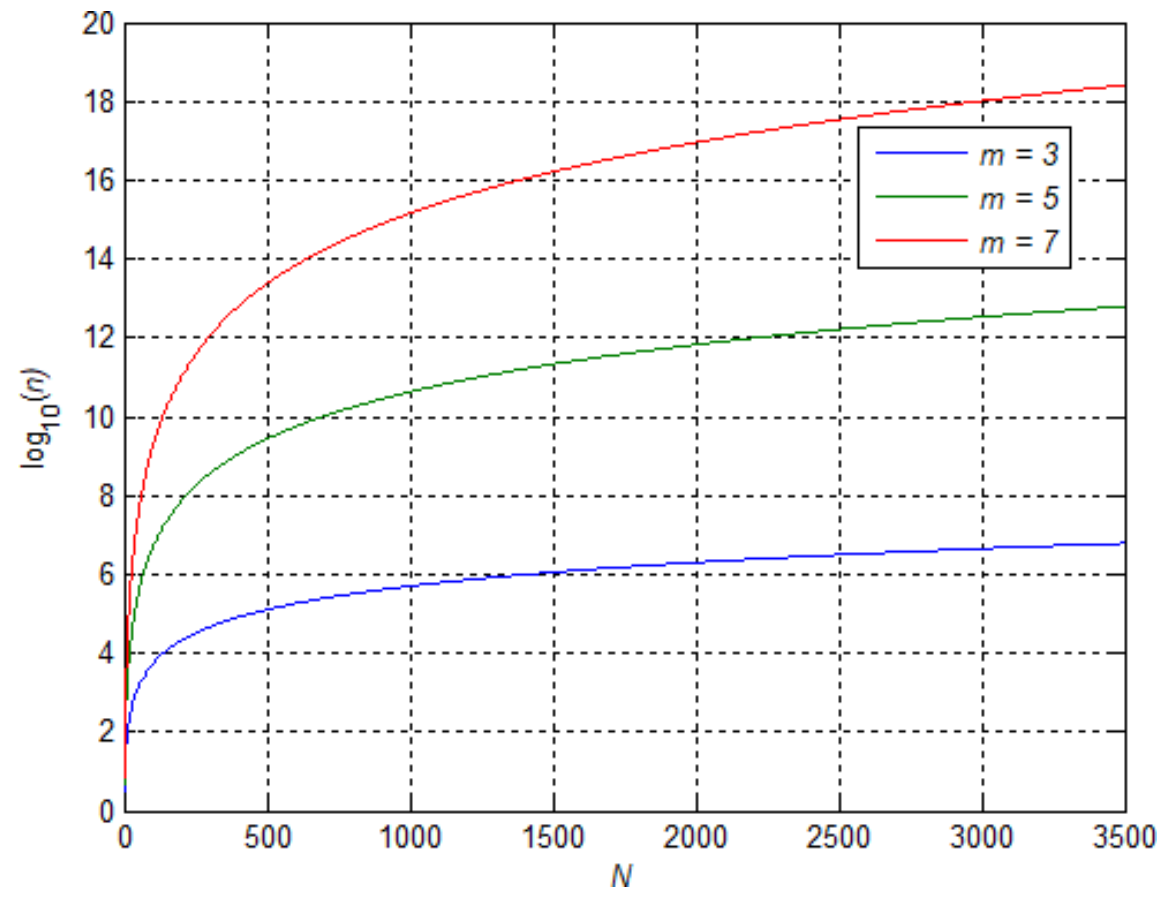



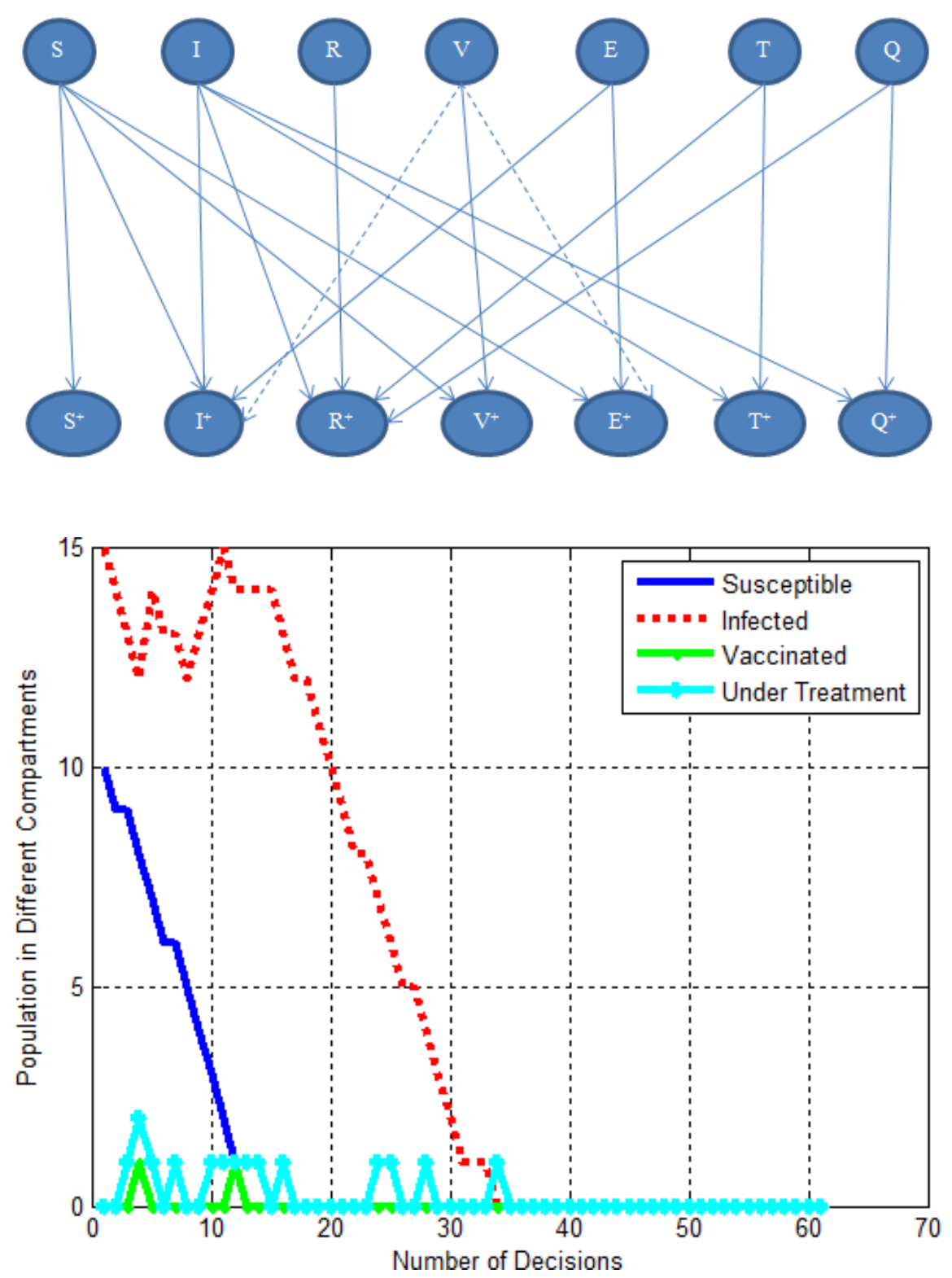


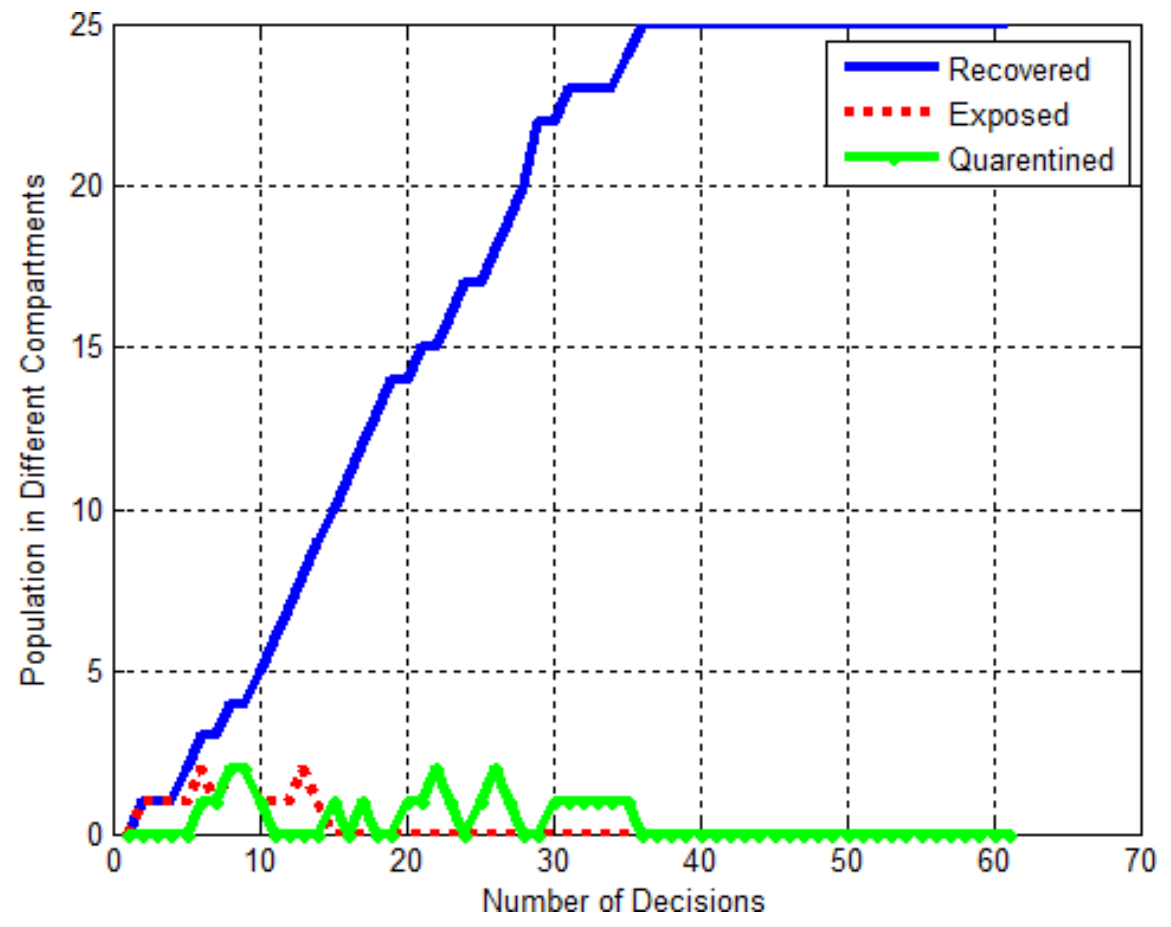

